\title{
A Teoria Interpretativa da Tradução (Théorie du Sens) revisitada: um novo olhar sobre a desverbalização*
}

Reynaldo J osé Pagura ${ }^{\dagger}$

\begin{abstract}
The Interpretive Theory of Translation, also known as Theory of Sense (Théorie du Sens), appeared in the 1960's from the thinking of Danica Seleskovitch as an interpreter, teacher, and researcher. Seleskovitch is soon joined by Marianne Lederer. It reaches its heyday in the 1980's, but in the 1990's begins to be questioned by empiricist theoreticians, who defend the use of research methods borrowed from the so-called "hard sciences" for interpreting and translation studies, an approach always rejected by both Seleskovitch and Lederer.

Interesting enough, after Seleskovitch's death ten years ago in 2001, the theory begins to be reexamined by several researchers in interpretation and translation, who begin to establish an interface between the théorie du sens and several other approaches to the study of translation and interpretation. They show that the concept of deverbalization, which is at the core of the interpretive theory of translation, is still very much alive and underlies many other translation and language theories, even when not specifically mentioned. This article intends to discuss these new looks at the concept of deverbalization, showing how alive and upto-date this concept is in today's translation and interpreting studies.
\end{abstract}

Keywords: interpretive theory of translation; sense; deverbalization; translation theories.

Resumo: A Teoria Interpretativa da Tradução, também conhecida como Théorie du Sens (Teoria do Sentido), surgiu na década de 1960, a partir da reflexão de Danica Seleskovitch como intérprete, professora e pesquisadora, a que se uniu Marianne

\footnotetext{
* Uma versão preliminar deste artigo foi apresentada, em forma oral, no Colóquio de Comemoração dos 50 Anos da Escola Superior de Intérpretes e Tradutores, Universidade Paris III (Sorbonne Nouvelle), em novembro de 2007. † Professor do Departamento de Inglês da Pontifícia Universidade Católica de São Paulo.
Email: reynaldop@uol.com.br.
} 
Lederer. Chega ao seu ápice em termos de aceitação na década de 1980, mas nos anos 1990 começa a ser questionada por teóricos empiricistas, que defendem o uso de metodologia de pesquisa quantitativa, utilizada em outras ciências, para os estudos da interpretação e da tradução. Tal abordagem sempre foi rejeitada por Seleskovitch e Lederer. Após a morte de Seleskovitch, em 2001, a teoria começa a ser reexaminada por diversos pesquisadores nos estudos da interpretação e da tradução, que começam a estabelecer interfaces entre a Théorie du Sens e outras diversas abordagens para os estudos da tradução e da interpretação. Demonstram que o conceito da desverbalização, que está no cerne da teoria interpretativa da tradução, continua em evidência e subjaz a diversas outras teorias da tradução e teorias linguísticas, mesmo quando não mencionado especificamente. 0 presente artigo pretendeu discutir esses novos olhares sobre o conceito da desverbalização, mostrando como tal conceito permanece atual nos estudos da tradução e da interpretação nos dias de hoje.

Palavras-chave: teoria interpretativa da tradução; sentido; desverbalização; teorias da tradução. 
Pagura, R. J . - A Teoria Interpretativa da Tradução (Théorie du Sens) revisitada: um novo olhar sobre a desverbalização

\section{O surgimento da teoria}

A Teoria Interpretativa da Tradução (TIT), também conhecida como Théorie du Sens [Teoria do Sentido], surgiu a partir da prática em interpretação de conferências, do exercício docente e da pesquisa acadêmica de Danica Seleskovitch e, posteriormente, Marianne Lederer, na École Supérieure d'Interprètes et de Traducteurs (ESIT), da Universidade Paris III, Sorbonne Nouvelle. A noção de desverbalização, que é um dos pontos centrais da Teoria do Sentido, apareceu formalizada pela primeira vez em 1968, quando Seleskovitch publicou sua primeira obra (SELESKOVITCH 1968, 1978), sendo desenvolvida em detalhes em sua tese de doutorado, defendida em 1973 e publicada em 1975 (SeleSKOVITCH 1975).

É preciso deixar bem claro que toda a reflexão teórica de Seleskovitch se dá a partir dos processos observados na interpretação de conferências (ou tradução oral), especificamente na interpretação consecutiva tradicional, em que o intérprete escuta longos trechos de um discurso ou todo o discurso, para só depois traduzi-lo oralmente. Exemplifica Seleskovitch em sua obra introdutória:

Imaginemos que acabamos de fazer um breve discurso de três minutos. Não seríamos capazes de repetir essas quatrocentas ou quinhentas palavras textualmente, com os gestos e a entoação originais, mesmo que nos fosse solicitado fazê-lo imediatamente após o fim do discurso. Normalmente, não saberíamos quais palavras e gestos utilizamos nem nós nem nossos ouvintes. 0 que nossa mente retém é o sentido, claro e preciso do que dissemos em voz alta, mas já registrados de maneira amorfa em nossa memória. A maioria das palavras pronunciadas (...) se apagaram na memória do orador e dos ouvintes, e apenas 0 sentido por elas transmitido permanece. Desse modo, tanto 0 orador como o ouvinte sabem "o que" foi dito (1978: 16). ${ }^{1}$

${ }^{1}$ Todas as traduções das citações originais em inglês ou francês são do autor do presente artigo. 
Pagura, R. J . - A Teoria Interpretativa da Tradução (Théorie du Sens) revisitada: um novo olhar sobre a desverbalização

O conceito da desverbalização surgiu, pois, originalmente dessa situação específica e não a partir da tradução escrita, nem mesmo da interpretação simultânea. LEDERER (1998) diz textualmente que "a desverbalização é um fenômeno natural na tradução oral, pelo menos na interpretação consecutiva. (...) Claramente visível na interpretação, a desverbalização é mais difícil de ser observada na tradução escrita" (meus grifos). Fica fácil perceber aqui a admissão de que pode não haver uma desverbalização completa nas outras modalidades de tradução, que não a interpretação consecutiva. LEDERER (1985) esclarece ainda que "a palavra escrita está sempre disponível, permitindo uma apreensão em ritmo mais lento". No entanto, diz ela, o leitor "apreende simultaneamente um certo número de signos, que se 'coagulam' em pequenos sentidos, cada um deles integrado aos seguintes para constituir o sentido geral do texto". SELESKOVITCH (1978) também faz questão de deixar clara a diferença entre a percepção do discurso oral e do texto escrito:

Quando a percepção auditória é comparada à percepção visual do texto escrito, que por sua própria natureza permite uma outra análise, permitindo que tanto as palavras quanto a forma permaneçam, chegamos à conclusão que a percepção auditória tem uma qualidade especial que permite separar o sentido do palavreado, permitindo que retenhamos assim o sentido e nos esqueçamos das palavras. (p.16).

É ainda importante lembrar que o raciocínio teórico de Seleskovitch veio a se opor às ideias correntes na Linguística da época, a saber, o gerativismo e o estruturalismo. Ela salienta constantemente a relação existente entre a língua e o mundo exterior, destacando que o processo tradutório ocorre em nível de parole e não de langue, utilizando-se da dicotomia saussuriana. "O estruturalismo de Bloomfield e Saussure se distanciou da relação língua-mundo exterior e língua-pensamento coletivo, para examinar nada mais do que as relações intralinguísticas, 0 funcionamento de um sistema, onde os fonemas se opõem e onde as palavras 
Pagura, R. J . - A Teoria Interpretativa da Tradução (Théorie du Sens) revisitada: um novo olhar sobre a desverbalização

se definem por oposição umas às outras" (SELESKOVITCH 1976). Reitera ainda a autora:

(...) estruturalistas como G. Mounin ou R. Jakobson que viram a tradução humana exclusivamente sob o ângulo do funcionamento da língua, e um gerativista como N. Chomsky, que trabalhou indiretamente a favor da tradução mecânica, não perceberam que, para estudar a tradução, deve-se abandonar o domínio dos sistemas de signos articulados, o domínio da competência linguística neutra de um "native speaker" [em inglês no original francês], a fim de penetrar no domínio do ato de comunicação que é, por sua vez, a realização da língua e a expressão de um pensamento individual, o domínio das mensagens transmitidas pela fala e que são, ao mesmo tempo, compostas da língua e de conteúdos cognitivos ligados aos signos linguísticos apenas de maneira transitória. 0 estudo da tradução exige que se levem em consideração não apenas a competência linguística do indivíduo que compreende e fala, mas também sua bagagem cognitiva e suas capacidades lógicas. (...) Compreender um texto ou discurso não consiste apenas em identificar os conteúdos semânticos permanentes dos signos linguísticos e a eles atribuir a significação que se depreende de sua combinação sintática em frases, mas também discernir os demais elementos cognitivos não-linguísticos que, em uma dada situação, estão ligados ao enunciado (1980: 403).

\title{
A desverbalização e a transcodificação
}

\author{
A desverbalização, posteriormente também mencionada como \\ “conceitualização" (Lederer 1981, Dej ÉAN LE FÉAL 1998), constitui o cerne da \\ TIT e é considerada fundamental para a apreensão do sentido. Resulta da \\ associação do significado linguístico das palavras com conhecimentos não- \\ verbais anteriores ("conhecimento enciclopédico") e com o "contexto de \\ situação", que é o conhecimento da situação em que o intérprete se \\ encontra, envolvendo informações tais como o tema da conferência, quem são \\ os oradores, qual a posição de cada um em relação a um determinado tópico \\ etc (LEDERER 1978, 1990).
}


Pagura, R. J . - A Teoria Interpretativa da Tradução (Théorie du Sens) revisitada: um novo olhar sobre a desverbalização

O processo interpretativo é resumido por SELESKOVITCH (1978) do seguinte modo:

1. Percepção auditiva de um enunciado linguístico que é portador de significado. Apreensão da língua e compreensão da mensagem por meio de um processo de análise e exegese;

2. Abandono imediato e intencional das palavras e retenção da representação mental da mensagem (conceitos, ideias, etc.);

3. Produção de um novo enunciado na língua-alvo, que deve atender a dois requisitos: expressar a mensagem original completa e ser voltado para o destinatário (p.9).

Seleskovitch enfatiza diversas vezes que um discurso oral se apresenta sem ruptura em sua continuidade e que um ouvinte não se concentra em palavras ou expressões isoladas para o entendimento da mensagem. Caso tente se deter em palavras isoladas ou qualquer outra marca linguística, rapidamente perderá a sua compreensão global (SELESKOVITCH 1981, 1991, 1996).

A transcodificação, por outro lado, é a tradução sem desverbalização, em que se traduzem as palavras de uma língua por equivalências convencionalmente pre-estabelecidas em outra língua. A TIT admite que deve haver transcodificação nos casos de números, nomes próprios, siglas e palavras técnicas específicas. Por exemplo, emphysema em inglês será automaticamente transcodificado em português por "enfisema"; carburator será "carburador", independente de contexto. Datas, quantias e outras expressões numéricas são normalmente anotadas pelo intérprete quando ouvidas em uma língua e, posteriormente, lidas na língua de chegada no momento certo do discurso, sem que seja necessário haver qualquer operação tradutória. O uso da anotação aqui desobriga o intérprete de ter de "traduzir" a expressão numérica, economizando também sua memória de trabalho.

Há ocasiões em que, devido à falta de compreensão do sentido, o intérprete acaba recorrendo à transcodificação pura e simples, até que consiga compreender o sentido de um trecho de discurso. Isso ocorre, 
Pagura, R. J . - A Teoria Interpretativa da Tradução (Théorie du Sens) revisitada: um novo olhar sobre a desverbalização

usualmente, no início de um discurso sendo interpretado em simultânea, quando o intérprete não depreendeu qual a intenção (vouloir-dire, na TIT) do orador. Dificilmente ocorrerá na consecutiva, em que o intérprete só traduz após ter ouvido um longo trecho do discurso na língua original. 0 intérprete voltará a recorrer à transcodificação caso haja opacidade no discurso em algum trecho ou quando for citada uma lista de nomes ou cifras e estatísticas. A essa alternância entre desverbalização e transcodificação, LEDERER (1981 1982) dá o nome de "movimento pendular", admitindo, desse modo, a sua existência.

Em resumo, o conceito de desverbalização surgiu da análise da interpretação consecutiva, feita da língua estrangeira para a língua materna do intérprete (LeDERER 1985), admitindo-se processos diferenciados na interpretação simultânea e na tradução escrita. Florence Herbulot, conhecida tradutora francesa e ex-presidente da Federação Internacional de Tradutores, chega a dizer que "Danica Seleskovitch começou por recusar que ela [a TIT] pudesse ser aplicada à tradução escrita. Foram os tradutores que a convenceram do contrário (HERBULOT 2004).

\section{Críticas à Teoria Interpretativa da Tradução}

A TIT sempre sofreu muitas críticas, pois, segundo a maior parte de seus críticos, as proponentes da teoria nunca provaram "cientificamente" a existência da desverbalização. No entanto, a tese de doutorado de Seleskovitch, já referida acima, e a de Lederer, publicada em 1981 (LEDERER 1981a) se apoiam em vastos corpora de gravações de interpretações de conferências. J ENSEN (1985), em um artigo dedicado quase inteiramente a criticar a TIT, inclui uma declaração pela qual, talvez, ele seja mais 
Pagura, R. J . - A Teoria Interpretativa da Tradução (Théorie du Sens) revisitada: um novo olhar sobre a desverbalização

conhecido do que por qualquer outra que já tenha feito: "Não se consegue provar que Seleskovitch esteja errada, do mesmo modo que ela não consegue provar que esteja certa".

Daniel Gile, matemático de formação e um dos mais prolíficos pesquisadores na área de interpretação de conferências, foi também um dos mais frequentes críticos da desverbalização e de outros postulados da TIT. Segundo ele, as afirmações das proponentes são sempre "categóricas demais e com uma série de comentários que não são provados por evidências suficientes". Questiona constantemente a falta de medidas empíricas (ver GILE 1995a). GILE (1995b) afirma ainda que "a 'teoria do sentido' dá a essa estratégia [a desverbalização] uma justificativa doutrinária que dispensa seus defensores de uma justificativa teórica ou experimental". No mesmo capítulo, justifica a "sólida implantação" da TIT por "fatores sociológicos", por ter Seleskovitch defendido o primeiro doutorado na França sobre interpretação, por ter ela criado o primeiro programa de doutoramento da área na França e por ter havido uma série de teses de doutoramento defendidas ainda nos anos 1970 nesse mesmo programa (ver GILE 1995b: 55). Em outra publicação, GILE (1995 (c)) refere-se à TIT como "engajada em uma teorização especulativa e introspectiva", opondo-a a uma tendência teórica surgida a partir de meados da década de 1980, a que ele denomina "aspirante à ciência". Em publicação posterior, GILE (2001, s/ pág. ) admite:

Um exemplo importante [sobre a reflexão a respeito da interpretação estimulada pela pesquisa] é o da "desverbalização", estágio da interpretação postulado por Seleskovitch no qual o discurso de origem desaparece completamente em sua forma linguística na mente do intérprete, e é substituído por um tipo de representação não linguística do seu "sentido". A existência de tal estágio na memória do intérprete nunca foi demonstrada, mas esse conceito é, no entanto, um dos principais na medida em que afirma a legitimidade da interpretação baseada no significado (oposta à interpretação baseada em palavras), e parece ser aceito e praticado por intérpretes e formadores de intérpretes em todo o mundo. (meu grifo). 
Pagura, R. J . - A Teoria Interpretativa da Tradução (Théorie du Sens) revisitada: um novo olhar sobre a desverbalização

PöCHHACKer (1995), um dos defensores do empiricismo afirma que "a pesquisa em interpretação ganhou novo ímpeto a partir de meados dos anos 1980. A longa dominação da escola de pensamento representada por Danica Seleskovitch (...) em Paris veio a ser desafiada pelos esforços de pesquisadores de vários locais, com abordagens e paradigmas diferentes, levando alguns a falar de uma "nova era" ou de um "Renascimento" na pesquisa em interpretação." Mas o mesmo autor já havia afirmado em publicação anterior (1992), ao analisar o papel da TIT: "De fato, Mme Seleskovitch merece total reconhecimento por ter feito oposição às estreitas concepções linguísticas a respeito da língua, que ainda prevaleciam no início dos anos 70".

SCHJ OLDAGER (1995) afirma que "como seus críticos repetidamente apontaram, essa "teoria" [a TIT] é, no máximo, uma hipótese tentativa que nunca foi empiricamente comprovada. Seria extremamente perigoso confundir tal hipótese com a teoria da interpretação. É triste notar “(...) que a maioria dos seus pesquisadores provavelmente não percebe tal fato".

Em resumo, todos os pesquisadores citados nesta seção do presente trabalho criticam a falta de comprovação empírica da desverbalização pelos proponentes da TIT, apesar dos inúmeros exemplos retirados de corpora de gravações reais apresentados pelos proponentes, principalmente por Lederer. Parece que as únicas provas aceitáveis para tais críticos seriam a quantificação, as medidas estatísticas que dominam as ciências naturais. É a eterna busca do cientificismo, que Seleskovitch sempre criticou nas teorias linguísticas, como já citado anteriormente (ver SeleSKOVITCH 1980). DejéAN LE FÉAL (1998) afirma que todos os pesquisadores apregoam que a "análise cognitiva é necessária na interpretação". Corroborando a ideia de Dejéan le Féal, sabe-se que muitos dos pesquisadores da chamada escola científica Barbara Moser-Mercer, Silvie Lambert, Dominique Masaro - são, de fato, psicólogos cognitivistas de formação. Continua Dejéan le Féal: 
Pagura, R. J . - A Teoria Interpretativa da Tradução (Théorie du Sens) revisitada: um novo olhar sobre a desverbalização

\begin{abstract}
Em meu entendimento, a desverbalização/ conceitualização é simplesmente a análise cognitiva levada ao extremo - o mesmo conceito, porém mais detalhado. De fato, não há indicação na literatura sobre a extensão em que a análise cognitiva deva ser empreendida. (...) Se os críticos da théorie du sens [em francês, no original inglês] especificassem até onde deve chegar a análise cognitiva, seria possível uma discussão mais objetiva da diferença entre os dois conceitos (p. 43).
\end{abstract}

Parece-nos que as duas "escolas de pensamento" sobre a interpretação discordam mais a respeito dos métodos de pesquisa do que sobre os postulados teóricos em si. Nenhum dos críticos da TIT conseguiu, até o momento, provar, por meio dos métodos por eles mesmos preconizados, que a proposta da desverbalização, que está no âmago da TIT, esteja errada. De fato, a conhecida frase de J ENSEN (1985) citada anteriormente, pode também ser lida da maneira inversa: Seleskovitch não consegue provar que está certa, do mesmo modo que não se consegue provar que esteja errada.

\title{
A desverbalização ressurge no século XXI
}

Coincidência ou não, após o falecimento de Seleskovitch em 2001, a ideia da desverbalização, preconizada por ela, vem sendo retomada por diversos pesquisadores em estudos recentes.

Robin Setton, pesquisador de interpretação sob a abordagem da pragmática, considera Seleskovitch como "uma pragmatista à frente de seu tempo" (Setton 2002). Ele demonstra seu uso de entrevistas em suas pesquisas, uma estratégia comum hoje em dia nas pesquisas sobre expertise e uma técnica usada comumente em estudos cognitivos de tradução, sob 0 
Pagura, R. J . - A Teoria Interpretativa da Tradução (Théorie du Sens) revisitada: um novo olhar sobre a desverbalização

nome de think-aloud protocols (TAPs). "No tocante à psicologia cognitiva, 0 modelo de memória de Seleskovitch está de acordo com o princípio respeitado da modularidade, em que processos diferentes competem por capacidade de atenção. (...) Sua leitura dos dados de interpretação nos termos deste modelo, apesar de impressionística, foi em si mesma uma importante contribuição original" (SETTON 2002). Setton salienta ainda o imenso esforço despendido [inutilmente] pelos opositores da TIT para torná-la apenas uma coisa do passado. Em sua conclusão, ele demonstra esperança: "À medida em que os estudos da interpretação amadurecem, talvez cheguemos a um momento além dos dogmas polarizantes, para reler, atualizar e integrar a perspicácia radical de Seleskovitch, num momento em que as ciências cognitivas estão começando a desenvolver contexto e representação intermediária nos modelos linguísticos e cognitivos" (SETTON 2002).

Antin Fougner Rydning, pesquisadora da Universidade de Oslo, na Noruega, em recente trabalho (RYDNING 2005), propõe-se a revitalizar a desverbalização, à luz da chamada blending theory (BT). Utilizando técnicas de TAP e o software Translog, que registra todos os passos do tradutor no computador, a pesquisadora demonstra, através de técnicas comumente utilizadas hoje em dia em pesquisa de tradução, como duas tradutoras (e não intérpretes) experientes "constroem o sentido". Utilizando o modelo da blending theory, a autora demonstra a percepção do sentido, na tradução do francês para o norueguês, mostrando a fusão (blending) de diversos conceitos na mente das tradutoras para chegarem a seu (diferente) resultado final no texto de chegada. A autora afirma que "as palavras [do original] agem meramente como sugestão para o sentido que nos levam a construir. Elas disparam a imaginação, onde projetamos conceitos dentro de outros conceitos" [o modelo da blending theory]. Segundo ela, a tradução "oferece a pesquisadores da ciência cognitiva um ponto de vista excepcional em um dos aspectos mais complexos da mente humana: a construção do sentido. Por outro lado, a BT [blending theory] parece oferecer aos teóricos da tradução 
Pagura, R. J . - A Teoria Interpretativa da Tradução (Théorie du Sens) revisitada: um novo olhar sobre a desverbalização

um modelo geral de construção de sentido que lhes permite dar conta dos mecanismos cognitivos que estão por trás da construção do sentido, o que é central em tradução" (RYDNING 2005). 0 modelo proposto pela blending theory parece provar a desverbalização por um mapeamento aceito pelas ciências cognitivas. Será que estamos vendo o início da comprovação científica sempre solicitada pelos detratores da TIT? Ou nada além de estatísticas será o suficiente?

Em artigo publicado no mesmo número da revista Meta, o pesquisador CLAUDE BoIsSon (2005) utiliza modelos do gerativismo mostrando que o processo da desverbalização de Seleskovitch, na tradução, pode ser integrado "em um modelo cujo módulo central é um sistema que permite a geração sistemática de formas lógicas variantes para as sentenças". Ele declara explicitamente na conclusão do artigo que seu objetivo é "esclarecer a natureza do processo de desverbalização e reverbalização" (p. 494) por meio da geração de "modelizações de conjuntos perifrásticos em abundância" (p. 494). Seria no mínimo curioso ouvir a opinião de Seleskovitch, caso estivesse viva, a respeito da "comprovação" de sua proposta de desverbalização por um modelo gerativista, linha teórica a cuja utilização ela tanto se opôs para a explicação do ato tradutório.

Por último cumpre mencionar o trabalho de J ean-René Ladmiral, ainda no mesmo número de Meta, que também se propõe, em longo artigo, a explicar a desverbalização. Segundo ele, "a tradução é caracterizada, a maior parte do tempo, pela descontinuidade da transferência da língua-fonte para a língua-alvo, operada por uma ruptura. Um procedimento de desverbalização ocorre entre o texto de partida, "que não existe mais" e o texto de chegada, "que ainda não existe". Mas o conceito de desverbalização permanece problemático, pois o sentido parece não existir sem um suporte, cuja natureza ainda não foi definida." (LADMIRAL 2005). O pesquisador reconhece, como já o fizeram Seleskovitch e Lederer, que o processo da interpretação consecutiva, do qual se originou o conceito de desverbalização, não é 0 
Pagura, R. J . - A Teoria Interpretativa da Tradução (Théorie du Sens) revisitada: um novo olhar sobre a desverbalização

mesmo da tradução escrita. Aponta duas diferenças fundamentais: a primeira é a volatilidade da linguagem oral, que se contrapõe à constância da escrita; a segunda é que na interpretação consecutiva, o original aparece em sequências longas, de modo que não pode ser estocada na memória imediata e traduzida instantaneamente como na interpretação simultânea. Parece claro que Ladmiral pretende destacar que a interpretação consecutiva é radicalmente diferente da interpretação simultânea e da tradução escrita, como já mencionado anteriormente neste trabalho. Em outras palavras, existe "mais desverbalização" na interpretação consecutiva do que na simultânea ou na tradução escrita, o que foi admitido originalmente pelos proponentes da TIT. Ladmiral recorre ao termo "para-verbal" para explicar a desverbalização, admitindo que não se trata de algo totalmente "não-verbal". Segundo ele, há diferentes níveis de comunicação verbal. É lapidar a sua explicação, e cumpre transcrevê-la na íntegra:

O conceito da desverbalização não pressupõe um momento da vida mental que seja mudo entre dois momentos de verbalização, mas sim que, entre esses dois, há necessariamente um desligamento da forma acabada e que se prende às normas das duas línguas em contato (língua de partida e língua de chegada). Parece incontestável que todas as nossas representações e toda a nossa comunicação não podem existir sem um "suporte". Mas esse suporte não é constituído, necessariamente, dos significantes de uma língua, de uma só língua, nem, sobretudo, são esses significantes constituídos de um enunciado bem formado, conforme às normas de uma determinada língua natural. (p. 479).

\section{Considerações finais}

Ladmiral fornece no parágrafo citado uma das explicações mais claras do que penso ser a desverbalização. Na interpretação consecutiva ela é, praticamente, uma necessidade, pois não é humanamente possível que se retenha o léxico e a estrutura sintática de vários minutos de um discurso. $\mathrm{Na}$ 
Pagura, R. J. - A Teoria Interpretativa da Tradução (Théorie du Sens) revisitada: um novo olhar sobre a desverbalização

interpretação simultânea, o discurso de partida encontra-se sempre mais presente na mente do intérprete, uma vez que a distância entre o momento em que se escuta o original e se enuncia a tradução oral na língua de chegada raramente é maior do que três a cinco segundos. A impressão da formulação linguística original é, de fato, muito mais presente do que na consecutiva e a desverbalização precisa ser consciente. Na tradução escrita, como já mencionado, o texto original está presente e pode ser consultado constantemente. É nesse processo que a desverbalização se torna mais difícil e precisa, até certo ponto, ser "forçada". Digo "precisa" propositadamente, pois todo tradutor sabe que não se podem converter apenas as estruturas e 0 léxico de uma língua para as estruturas e o léxico de outra, sob pena de ter um texto de chegada não-idiomático. Há circunstâncias em que, obviamente, a proximidade entre sintaxe e léxico das duas línguas em contato permite uma transcodificação, para se usar a terminologia da TIT. Em outros, no entanto, fica claro que o tradutor tem de compreender o que diz o texto de partida e reexpressá-lo na língua de chegada, sem se deter na repetição da sintaxe da língua de partida ou na escolha lexical calcada em cognatos dessa mesma língua na língua de chegada. É o chamado "movimento pendular" de Lederer, também já mencionado. É óbvio que não se trata aqui da tradução de poesia, mas principalmente da de textos pragmáticos.

É no mínimo curioso notar que Meta, talvez o mais lido e, possivelmente, um dos mais antigos e prestigiados periódicos científicos de Estudos da Tradução, traga em um mesmo número recente, em seu 50 ano de publicação, diversos artigos que se proponham a reabilitar ou explicar 0 conceito de desverbalização, proposto por SELESKOVITCH (1968) há várias décadas. O conceito que, segundo seus críticos, deveria estar morto por nunca ter sido provado "cientificamente" parece continuar a despertar 0 interesse de diversos pesquisadores não só da interpretação, como de fato se propunha em sua origem, mas de tradução na sua modalidade escrita. São pesquisadores de diferentes escolas de pensamento e de diferentes 
Pagura, R. J . - A Teoria Interpretativa da Tradução (Théorie du Sens) revisitada: um novo olhar sobre a desverbalização

instituições, que tentam explicar a desverbalização à luz de diferentes teorias.

Concluo fazendo minhas as palavras de Paulo Rónai, que resumem, para a tradução escrita e sem mencionar o termo, o próprio conceito da desverbalização, conforme proposto por Seleskovitch: "O tradutor mais fiel, já disse, seria aquele que, graças a uma capacidade excepcional, estivesse em condições de esquecer as palavras da mensagem original e, logo depois, de lembrar-se de seu conteúdo, para reformulá-la na própria língua, de maneira mais completa" (Rónal 1981).

\section{Referências bibliográficas}

Bolsson, C. La forme logique et les processus de déverbalisation et de réverbalisation en traduction. Meta, 50, 2, 2005.

Dej ean le FÉAL, K. Non nova, sed nova. The Interpreters' Newsletter, 8, 41-49, 1998.

GILE, D. Basic concepts and models for interpreter and translator training. Amsterdã/ Filadélfia: J ohn Benjamins, 1995 (a).

- Regards sur la recherche en intérpretation de conférence. Lille: Presses Universitaires de Lille, 1995 (b).

- Interpretation research: a new impetus? Hermes, Journal of Linguistics, 14, 1995 (c).

. Interpreting Research-What you never wanted to ask but may like to know. Communicate! (órgão informativo da Associação Internacional de Intérpretes de Conferência], Genebra, março-abril de 2001.

HERBULOT, F. La théorie interprétative ou théorie du sens: point de vue d'une praticienne. Meta, 49, 2, 2004.

J ENSEN, P. A. SI: A note on error typologies and the possibility of gaining insight in mental processes. Meta, 30, 1, 1985. 
Pagura, R. J . - A Teoria Interpretativa da Tradução (Théorie du Sens) revisitada: um novo olhar sobre a desverbalização

LEDERER, M. Simultaneous interpretation-units of meaning and other features. In: Gerver, D. e H. Wallace Sinaiko (orgs). Language interpretation and communication. Nova York: Plenum Press, 1978.

- La traduction simultanée-expérience et théorie. Paris: Minard, 1981(a).

. La pedagogie de la traduction simultanée. In: DeLISLE, J. L'enseignement de l'interprétation et de la traduction. Cahiers de traductologie:4. Ottawa: Editions de l'Université d'Ottawa, 1981 (b).

. Le processus de la traduction simultanée. Multilingua, 1,3, 1982.

. L'interprétation, manifestation élémentaire de la traduction. Meta, 30, 1, 1985.

. The role of cognitive complements in interpreting. In: Bowen, D. e M. Bowen. Interpreting - yesterday, today, and tomorrow. American Translators Association Scholarly Monograph Series. Binghamton (N.Y.): State University of New York, 1990.

. The interpretive theory of translation: a brief survey. El Lenguaraz Revista academica del Colegio de Traductores Públicos de la Ciudad de Buenos Aires, 1, 1, 1998.

PÖCHHACKER, $F$. The role of theory in simultaneous interpreting. In: C. DOLLERUP e A. LINDEGAARD (orgs.), Teaching translation and interpreting: training, talent and experience. Amsterdã: J ohn Benjamins, 1992.

RónAl, P. A tradução vivida. 2a. ed. rev. e aum. Rio de Janeiro: Nova Fronteira, 1981.

RYDNING, A. F. The return of sense on the scene of translation studies in the light of the cognitive blending theory. Meta, 50, 2, 2005.

SCHJ OLDAGER, A. Interpreting research and the 'Manipulation School' of Translation Studies. Target, 7, 1, 1995.

"Those who do...": a profile of research(ers) in interpreting. Target, 7:1. 47-64, 1995.

SeleSKovitCH, D. L'interprète dans les conférences internationales. Paris: Minard, 1968.

- Langage, langues et mémoire: étude de la prise de notes en interprétation consécutive. Paris: Minard, 1975.

. De I'expérience aux concepts. Études de Linguistique Appliquée, 24, Paris: Didier, 1976. 
Pagura, R. J . - A Teoria Interpretativa da Tradução (Théorie du Sens) revisitada: um novo olhar sobre a desverbalização

- Interpreting for international conferences. Tradução de L'interprète dans les conférences internationales. Washington: Pen and Booth, 1978.

.1980. Pour une théorie de la traduction inspirée de sa pratique. Meta, v. 25, n. 4. pp. 401-408. Montreal: Presses de I'Université de Montréal.

. L'enseignement de la interprétation. In: DeLISLE, J. L'enseignement de I'interprétation et de la traduction. Cahiers de traductologie: 4. Ottawa: Editions de l'Université d'Ottawa, 1981.

. De la pratique de l'interprétation à la traductologie. In: Lederer, M. e F. Israel. La liberté en traduction. Paris: Didier Érudition, 1991.

- Interpretation and verbal communication. In: Lauer, A. et al. Übersetzungswissenschaft im Umbruch. Tübingen: Gunter Narr Verlag, 1996.

SETTON, R. Revisiting the classics - Seleskovitch: A radical pragmatist before her time. The Translator, 8, 1, 2002. 